\title{
Quantitative measurement of biliary excretion and of gall bladder concentration of drugs under physiological conditions in man
}

\author{
A LANZINI, M G PIGOZZI, A WUHRER, D FACCHINETTI, \\ M CASTELLANO, L BETTINI, U P GUERRA, M BESCHI, AND G MUIESAN \\ From the Department of Clinical Medicine, University of Brescia and Nuclear Medicine Unit, Spedali Civili, \\ Brescia, Italy
}

SUMMARY Gall bladder storage of hepatic bile prevents complete recovery of biliary excretion of drugs to be obtained under physiological conditions in man. The aim of this study was to develop and validate a method for simultaneous measurement of gall bladder storage of a cholephilic drug, and of its duodenal excretion and $t_{1 / 2}$ in bile. Duodenal perfusion using polyethylene glycol as intestinal recovery marker for measurement of drug duodenal excretion, with an iv bolus of ${ }^{99 m}$ Tc HIDA for measurement of drug mass within the gall bladder was used. Gall bladder volume was measured by ultrasonography. $T_{1 / 2}$ in bile was measured by relating drug duodenal excretion to that of bile acid used as an endogenous bile marker. The use of bile acid as biliary marker was validated in two subjects receiving simultaneous iv infusion of indocyanine green. Seven healthy subjects were studied using a beta-lattam antibiotic, Cefotetan $1 \mathrm{~g}$ iv, as test drug. Median values during the study period (seven hours) were $51 \cdot 1 \mathrm{mg}$ for Cefotetan duodenal excretion, $45 \cdot 2 \mathrm{mg}$ for gall bladder mass and $2.8 \mathrm{mg} / \mathrm{ml}$ for concentration within the gall bladder. $T_{1 / 2}$ of the drug in bile was 100 minutes. This technique enables measurement of mass and concentration of drugs within the gall bladder to be carried out, in addition to measurements of $t_{1 / 2}$ of drugs in bile. These measurements may have specific application for assessment of potential efficacy of antibiotics in biliary tract infections, as well as general application for assessment of biliary excretory kinetics of drugs.

Current methodology for measurement of biliary excretion of drugs and biliary pharmacokinetics is unsatisfactory. ${ }^{1}$ Methods based on biliary drainage through a $T$ tube after cholecystectomy ${ }^{2}$ may not ensure quantitative recovery of biliary secretions. Furthermore, results may be affected by the underlying disease. Methods based on duodenal perfusion techniques can, on the one hand, be applied to healthy subjects but, on the other hand, are of limited value because the mass of drug stored in the gall bladder is neglected. This gall bladder mass is likely to account for a major proportion of drug biliary

Address for correspondence: Dr Alberto Lanzini, Clinica Medica, Spedali Civili, Piazzale degli Spedali, 25100 Brescia, Italy.

Received for publication 30 June 1988. excretion, because about $50 \%$ to $80 \%$ of hepatic bile is stored in the gall bladder during fasting..$^{3.5}$ Attempts to abolish gall bladder storage function by using a continuous intraduodenal infusion of nutrients $s^{6-9}$ has been recently shown by Everson $e t a^{10}$ to be ineffective because of failure to maintain the gall bladder tonically contracted.

A method combining cholescintigraphy with nasoduodenal intubation has recently been developed for measurement of gall bladder storage function in healthy subjects ${ }^{11}$ and has been applied to measurement of biliary lipid mass stored in the fasting gall bladder. It is of potential value for measuring the mass of drug in the gall bladder.

The aim of this study was to apply this method to quantitative measurement of gall bladder mass of a cholephilic test drug; and to combine this technique 


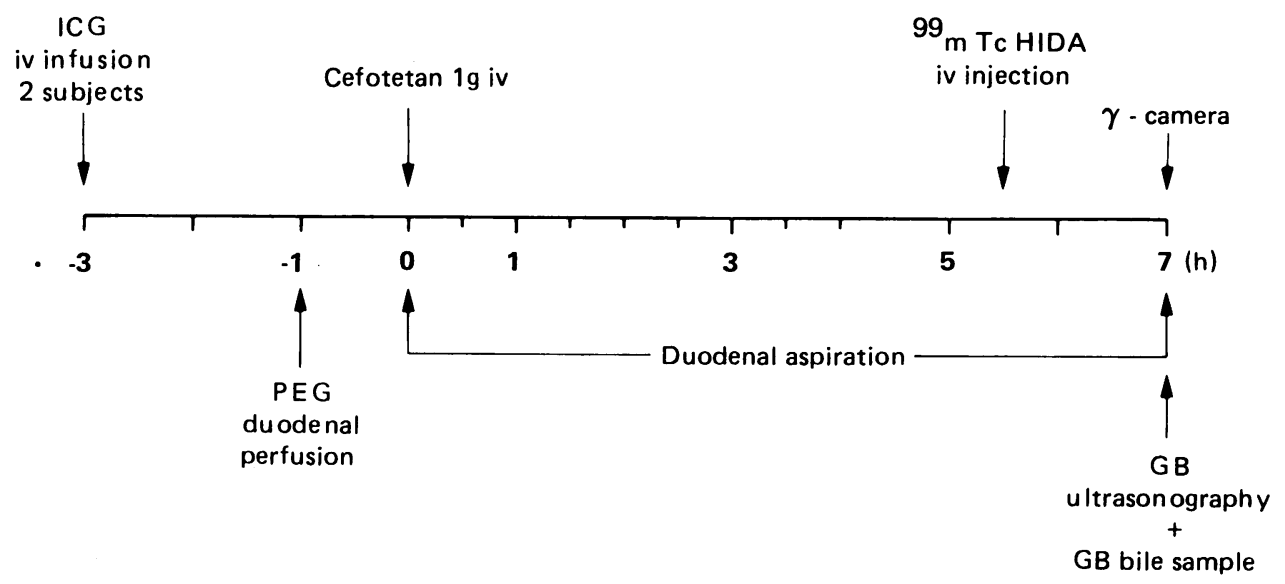

Fig. 1 Time table of the study (ICG=indocyanine green, $P E G=$ polyethylene glycol and $G B=$ gall bladder).

with measurements of duodenal excretion rates in order to obtain quantitative measurement of total biliary excretion of drugs under physiological conditions in man. Further aims were to measure the drug concentration within the fasting gall bladder, and its half-life in bile. A duodenal perfusion of polyethylene glycol (non-absorbable intestinal recovery marker) was used for measurement of duodenal excretion $^{5}$ of a test drug. A cholescintigraphic technique involving ${ }^{99_{\mathrm{m}}} \mathrm{Tc}$ HIDA (gall bladder bile marker) given as an iv bolus was used for measurement of drug mass within the gall bladder. ${ }^{511}$ This latter measurement was related to gall bladder volume as measured by ultrasonography ${ }^{12}$ in order to measure drug concentration within the gall bladder. The half life $\left(t_{1 / 2}\right)$ of the test drug in bile was measured by relating its duodenal excretion rate to that of an endogenous biliary marker, bile acid. We applied this combination technique to five healthy volunteers. Two further subjects were studied during a continuous iv infusion of indocyanine green (ICG, exogenous biliary marker) in order to validate bile acid as an endogenous biliary marker. As test drug we used a beta lattam antibiotic, Cefotetan.

\section{Methods}

\section{SUBJECTS}

We studied seven healthy volunteers (five women, two men; age range 28-51 years, mean (SE) 48.3 $(4 \cdot 5)$ years) with normal physical examination, blood count, and liver function tests. Creatinine clearance was $>125 \mathrm{ml} /$ minute in each subject. Informed consent was obtained from all subjects. Radiation exposure was calculated to be $<0.5 \mathrm{rad}$ for the whole gut.
CLINICAL PROCEDURE (Fig. 1)

On the day before the study, the subjects were admitted to a clinical investigation ward. On the following morning, a double lumen nasoduodenal tube (Anpro-20, Andersen, USA) was advanced under fluoroscopic control in the fasting state to position the proximal outlet (duodenal perfusion tube, id $1 \mathrm{~mm}$ ) opposite the ampulla of Vater. The distal tube (aspiration tube, id $2.5 \mathrm{~mm}$ ) was positioned at the ligament of Treitz, allowing $20 \mathrm{~cm}$ mixing segment. This distal tube was radiopaque, and radiopaque marks were also attached at the distal end of the perfusion tube to assist correct fluoroscopic positioning.

Two and a half grams per litre polyethylene glycol solution (PEG, mw 4000) was prepared in normal saline and continuously perfused into the duodenum (Fig. 1) at the rate of $5 \mathrm{ml} / \mathrm{min}$ by a peristalstic pump (model 502S, Watson Marlow, UK). After allowing 60 minutes to achieve a steady state, $1 \mathrm{~g}$ Cefotetan (ICI, UK) was injected as a single iv bolus, and duodenal aspirate was obtained by syphonage at 30 minute intervals for four hours and at hourly intervals thereafter for a total seven hours. As part of a validation study, two of the seven subjects were studied during continuous iv infusion of ICG. The ICG solution (Indocyanine green, HW\&D, USA) was prepared in normal saline containing $5 \%$ human albumin immediately before the study. Intravenous infusion started three hours before Cefotetan administration (Fig. 1), to allow equilibration of hepatic output with its iv input, ${ }^{313}$ and continued until the end of the study at a constant rate of $0.2 \mathrm{mg} / \mathrm{kg} / \mathrm{h}$ (model 975, Harvard Infusion Pump, USA). The ICG solution was kept in the dark during preparation and iv administration. 
Two millicuries ${ }^{99 m} \mathrm{Tc}$ HIDA ${ }^{9{ }^{9 m} \mathrm{~T}} \mathrm{Tc}$ sodium $\mathrm{n}$-[n(2,6-diethylphenlyl-carbamylmethyl)] iminodiacetate, Amersham, UK) was injected as an iv bolus in five subjects 90 minutes before the end of the duodenal perfusion of polyethylene glycol. Two hours later, anterior and posterior abdominal gamma camera counting (one minute interval) was carried out with a gamma camera/computer system (model KR7, SELO, Italy). Data were stored in the computer and later reanalysed using an area of interest facility to outline the gall bladder area. Interference for liver background activity was corrected by subtracting from gall bladder counts the activity detected in an equivalent area of the liver adjacent to the gall bladder. Differences in gall bladder depth from the gamma camera crystal were compensated for by using the formula: ${ }^{11} \mathrm{~GB}$ counts= (anterior GB counts ${ }^{2}+$ posterior GB counts $)^{1 / 2}$ (where $\mathrm{GB}=$ gall bladder).

After gall bladder gamma camera scanning, gall bladder volume was measured by real time ultrasonography (model MK $300 \mathrm{C}$, sector probe $3.0 \mathrm{MHz}$, ATL, USA) as described by Everson et al. ${ }^{11}$ A sample of gall bladder bile was later obained by stimulating gall bladder contraction with iv infusion of caerulein solution (20 $\mu \mathrm{g}$ in $100 \mathrm{ml}$ normal saline, Farmitalia, Italy).

\section{LABORATORY METHODS}

Polyethylene glycol concentration in duodenal aspirate was measured by the turbidometric method of Hyden. ${ }^{14}$ Cefotetan concentration was measured by HPLC (model 590, Waters, USA) as described by Adam et al. ${ }^{15}$ Bile acid concentration was measured enzymatically, ${ }^{16}$ and ICG was measured spectrophotometrically within 24 hours from collection as previously described. ${ }^{4}{ }^{99 m} \mathrm{Tc}$ HIDA activity in $1 \mathrm{ml}$ gall bladder bile samples was measured for 10 seconds with a gamma counter (model ST5, SELO, Italy). In order to relate measurements obtained with gamma counter and gamma camera [see (ii) in calculations], a correction factor was applied to take account of their different sensitivites for ${ }^{99 m}$ Tc HIDA detection (1/2054). Time dependent decay of ${ }^{99 m} \mathrm{Tc}$ HIDA activity and differences in counting time were also taken into account.

CALCULATIONS AND EXPRESSION OF RESULTS Duodenal excretion of Cefotetan, bile acid and ICG was calculated according to the following formula:

$$
\text { (i) } \mathrm{C}_{\mathrm{de}}\left(\text { or } \mathrm{Ba} \text { or ICG) }=[\mathrm{C} \text { or } \mathrm{Ba} \text { or ICG }] \times \frac{[\mathrm{PEG}]_{\mathrm{p}}}{[\mathrm{PEG}]_{\mathrm{a}}} \times \mathrm{v} \times \mathrm{t}\right.
$$

Where de =duodenal excretion $\mathrm{C}=$ Cefotetan, $\mathrm{Ba}=$ bile acid, $I C G=$ indocyanine green, $P E G=$ polyethylene glycol, []$=$ concentration, $a=$ duodenal aspirate, $p=$ duodenal perfusate, $v=$ volume of duodenal perfusate, $t=$ time of duodenal perfusion.

Gall bladder mass of Cefotetan was calculated according to the following formula:
(ii) $\mathrm{C}_{\mathrm{m}}$ in $\mathrm{GB}=$
$\mathrm{C}_{\mathrm{m}}(1 \mathrm{ml} \mathrm{GB}$ bile $) \times{ }^{9 m} \mathrm{Tc}$ HIDA activity over the Gb area ${ }^{9 m}$ Tc HIDA activity ( $1 \mathrm{ml} \mathrm{GB}$ bile)
where ${ }_{m}=$ mass and $\mathrm{GB}=$ gall bladder

Total biliary excretion of Cefotetan was calculated according to the following formula:

\section{(iii) $\mathrm{C}_{\mathrm{b}}=$ (i) + (ii)}

where $_{b}=$ biliary excretion

Concentration in the gall bladder of Cefotetan was calculated according to the following formula:

(iv) $\mathrm{C}_{\mathrm{c}}=\mathrm{C}_{\mathrm{m}} / \mathrm{GB}$ volume where $\mathrm{c}=$ concentration

\section{Subject 1}

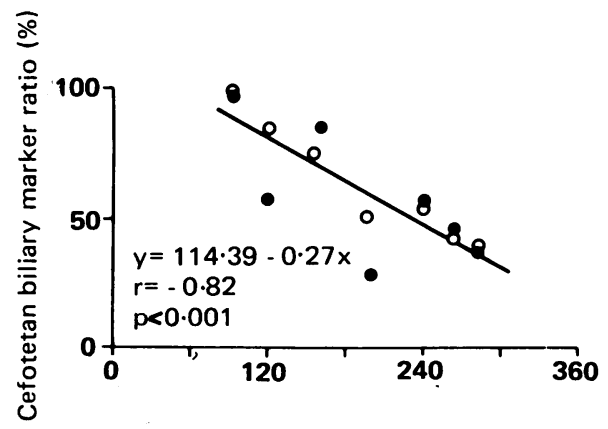

Fig. 2 Reproducibility of Cefotetan/indocyanine green ratio (open circles) and of Cefotetan/bile acid ratio (closed circles) in two subjects studied during continuous iv infusion of ICG. 


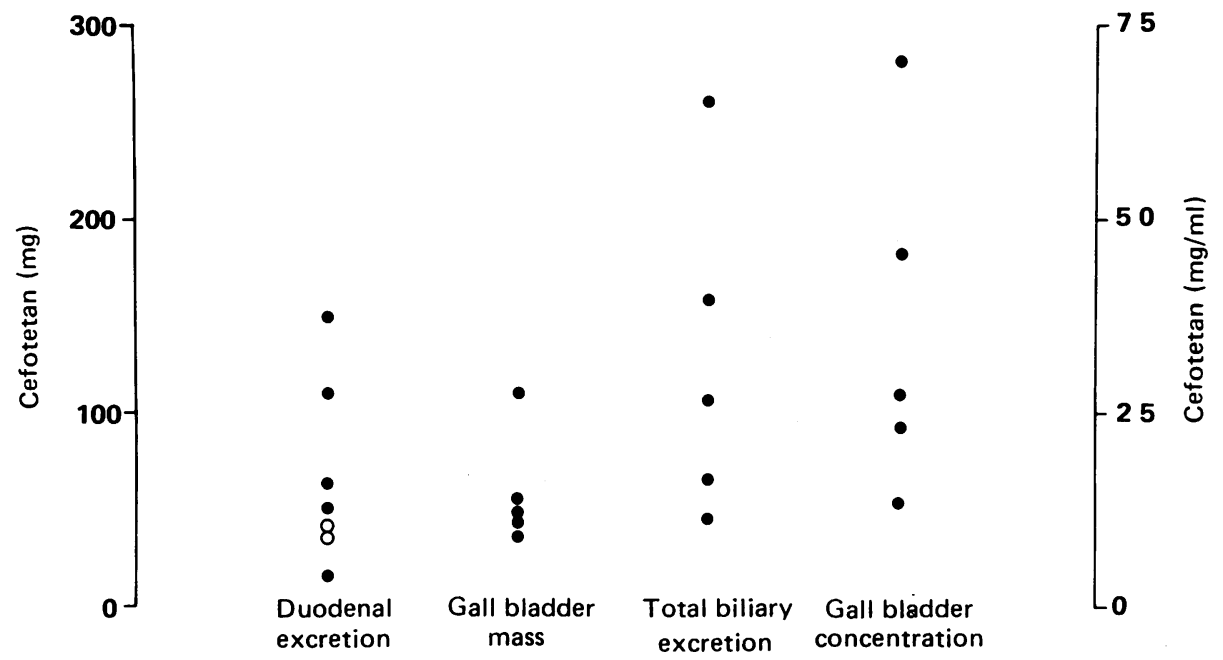

Fig. 3 Duodenal excretion, gall bladder mass, total biliary excretion and concentration of Cefotetan in the gall bladder. Subjects marked $(O)$ were studied during indocyanine green iv infusion.

Cefotetan/bile acid and Cefotetan/ICG ratios were calculated from duodenal outputs (i). Absolute values for both measurements were expressed as a percent of the peak values, which were considered to be $100 \%$.

(v) $\mathrm{C} / \mathrm{Ba}=\mathrm{C}_{\mathrm{de}} / \mathrm{Ba}_{\mathrm{de}}$ $\mathrm{C} / \mathrm{ICG}=\mathrm{C}_{\mathrm{de}} / \mathrm{ICG}_{\mathrm{de}}$

$\mathrm{T}_{1 / 2}$ in bile of Cefotetan was defined as the time taken for both $\mathrm{C} / \mathrm{Ba}$ and $\mathrm{C} / \mathrm{ICG}$ ratios to reach $50 \%$ of the peak value.

\section{STATISTICAL ANALYSIS}

Results were expressed as median values. Regression lines were calculated using the least square method. The linearity was tested by fitting a power curve to log transformed variables, a power less than 1 indicating a curvilinear relationship.

\section{Results}

VALIDATION STUdies (Fig. 2)

Cefotetan/bile acid ratio and Cefotetan/ICG ratio declined with time in both subjects studied during ICG intravenous infusion. A single regression line was derived for the combined data from the two measurements in both subjects, and the data from both individual measurements were equally distributed around this regression line.

\section{GALL BLADDER MASS AND CONCENTRATION} (Table, Fig. 3)

The mass of Cefotetan stored in the gall bladder in the five subjects studied ranged from 17.9 to $111.9 \mathrm{mg}$ ( $45.2 \mathrm{mg}$ median value). Gall bladder volume in individual subjects ranged from 10.6 to $21.1 \mathrm{ml} \mathrm{(16.4}$ $\mathrm{ml}$ median value). Cefotetan concentration in the gall bladder ranged from 1.4 to $7 \cdot 1 \mathrm{mg} / \mathrm{ml}(2.8 \mathrm{mg} / \mathrm{ml}$ median value).

BILIARY EXCRETION (Table, Fig. 3)

Cumulative duodenal excretion of Cefotetan in the seven subjects studied ranged from 18.4 to $151.9 \mathrm{mg}$ (51.1 mg median value) during the seven hours study. Total biliary excretion (duodenal excretion plus gall bladder mass) ranged in individual subjects from 47.2 to $263.8 \mathrm{mg}$ (108.6 median value).

$T_{1 / 2}$ IN BILE (Figs 4 and 5)

The profile of Cefotetan duodenal excretion in

Table Individual values for duodenal excretion, gall bladder (GB) mass and total biliary excretion of Cefotetan in the seven subjects studied. Gall bladder volume and Cefotetan concentration in the gall bladder are also shown

\begin{tabular}{llllll}
\hline & $\begin{array}{l}\text { Duodenal } \\
\text { excretion } \\
(\mathrm{mg})\end{array}$ & $\begin{array}{l}\text { GB mass } \\
(\mathrm{mg})\end{array}$ & $\begin{array}{l}\text { Total } \\
\text { biliary } \\
\text { excretion } \\
(\mathrm{mg})\end{array}$ & $\begin{array}{l}\text { GB } \\
\text { volume } \\
(\mathrm{ml})\end{array}$ & $\begin{array}{l}\text { GB con- } \\
\text { centration } \\
(\mathrm{mg} / \mathrm{ml})\end{array}$ \\
\hline 1 & $51 \cdot 1$ & 17.9 & $69 \cdot 0$ & $21 \cdot 1$ & $2 \cdot 4$ \\
2 & 18.4 & 28.8 & 47.2 & $21 \cdot 1$ & 1.4 \\
3 & 151.9 & 111.9 & 263.8 & $15 \cdot 8$ & 7.1 \\
4 & 63.4 & 45.2 & 108.6 & 16.4 & 2.8 \\
5 & 111.6 & 48.9 & 160.5 & 10.6 & 4.6 \\
6 & 44.4 & - & - & - & - \\
7 & 39.0 & - & - & - & - \\
\hline
\end{tabular}




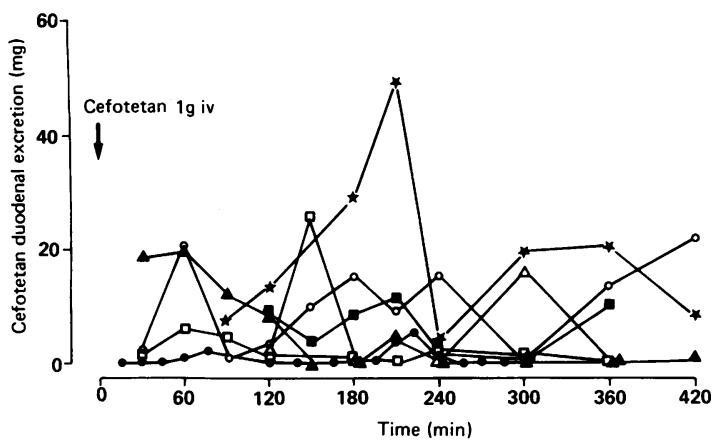

Fig. 4 Duodenal excretion rate of Cefotetan $(\mathrm{mg} / \mathrm{h})$ in individual subjects. Each subject is identified by a different symbol.

individual subjects is shown in Figure 4. Hourly Cefotetan duodenal excretion fluctuated during the whole study period in all subjects, and there was no relationship between Cefotetan duodenal excretion and time $(r=0 \cdot 11, \mathrm{NS})$. By contrast, there was a decline of Cefotetan/bile acid ratio with time in pooled data from all subjects. This relationship was better described by a curve $\left(y=979.5 \times X^{-0.684}\right.$, $\mathrm{r}=0.315, \mathrm{p}<0.05)$ than by a straight line. $\mathrm{T}_{1 / 2}$ of Cefotetan in bile calculated on this curvilinear relationship was 100 minutes.

\section{Discussion}

Our validation study has shown that $t_{1 / 2}$ of a cholephilic substance in bile can be measured under

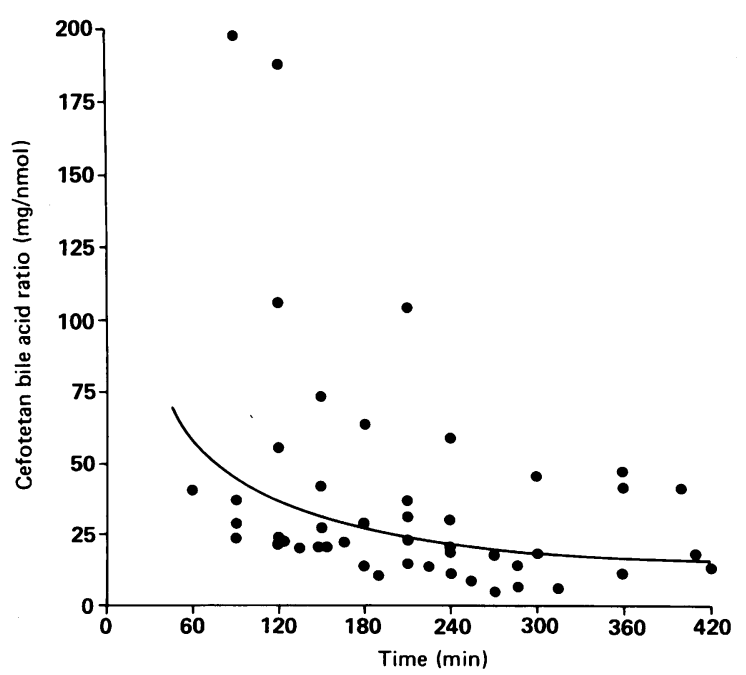

Fig. 5 Relationship between Cefotetan/bile acid ratio ( $\mathrm{mg} /$ $m M)$ and time in all subjects studied. physiological conditions in man by using bile acid as an endogenous biliary marker. The validity of this measurement was confirmed by comparison with results based on ICG as an exogenous biliary marker. The reason for choosing ICG as control bile marker was that ICG acts as an ideal biliary marker, as indicated by its complete duodenal recovery in cholecystectomised subjects. ${ }^{3513}$

We have previously validated the duodenal perfusion technique by showing $102 \%$ duodenal recovery of a gall bladder bile marker, ${ }^{99 \mathrm{~m}} \mathrm{Tc}$ HIDA. ${ }^{5}$ Measurement of the mass of cholephilic substances in the gall bladder using ${ }^{99 m} \mathrm{Tc}$ HIDA cholescintigraphy has also been validated by Jazrawi et $a l^{17}$ by direct comparison with measurements obtained in surgically removed gall bladders.

The combination of a cholescintigraphy technique with a duodenal perfusion technique has enabled quantitative measurement of gall bladder mass and concentration, and of total biliary excretion of drugs to be carried out under physiological conditions in man. These measurements have several potential applications. In relation to safety of drugs like parenteral antibiotics, dose dependent changes in colonic flora caused by biliary excretion may occur, ${ }^{18}$ thus underlining the importance of quantitative measurement of the amount of drug entering the intestine. In relation to drug efficacy, although therapeutic serum concentrations of an appropriate antibiotic may often prevent complications of biliary tract infections, ${ }^{1}$ eradication of bacteria from bile may be difficult as indicated by the high incidence of septic complications in biliary surgery. ${ }^{19}$ Eradication of bacteria from bile is only guaranteed by a therapeutic biliary concentration of an antibiotic.' ${ }^{1}$ Our technique for measuring drug concentration in gall bladder bile provides a simple and cheap method of obtaining this information. In the case of Cefotetan, drug concentration in the gall bladder bile was 21- to 71-fold greater in individual subjects than the minimal inhibitory concentration measured in vitro for sensitive bacteria. ${ }^{20}$

A further advantage of our technique is that it also enables measurement of drug $t_{1 / 2}$ in bile to be carried out by using bile acids as an endogenous biliary marker. The advantage of calculating the ratio of Cefotetan to bile acid is born out by visual comparison of Figure 4 with Figure 5. Duodenal excretion of the antibiotic fluctuated during the whole study in all subjects (Fig. 4), probably as a result of sphincter of Oddi activity ${ }^{21}$ and/or changes in gall bladder storage and emptying function. ${ }^{5}$ There was no relationship between Cefotetan duodenal output and time (Fig. 4 ), and biliary $t_{1 / 2}$ could not be measured on these results. By contrast, results for Cefotetan/bile acid ratio were inversely related with time, thus enabling 
calculation of $t_{1 / 2}$ of the drug in bile to be carried out (100 minutes). The high value for $t_{1 / 2}$ of Cefotetan is consistent with the strong binding of this antibiotic to serum proteins, and with its high serum $\mathrm{t}_{1 / 2} \cdot{ }^{22}$

In conclusion, our results indicate that we have a valid and simple technique for the quantitative measurement of biliary excretion and gall bladder concentration of drugs under physiological conditions in man. This technique should be of specific value in the case of cholephilic antibiotics.

Part of this work was presented at the Medical Research Society Meeting in December 1986, and published in abstract form in Clin Sci 1986; 70: 72P. The authors wish to thank ICI-Pharma, Milan, Italy for financial support, and Farmitalia, Milan, Italy for kindly supplying caerulein free of charge.

\section{References}

1 Dooley JS, Hamilton-Miller JMT, Brumfitt W, Sherlock S. Antibiotics in the treatment of biliary infections. Gut 1984; 25: 988-98.

2 Acocella G, Mattiussi R, Nicolis FB, Pallanza R, Tenconi LT. Biliary excretion of antibiotics in man. Gut 1968; 9: 536-45.

3 Van Berge Henegouwen GP, Hofmann AF. Nocturnal gallbladder storage and emptying in gallstone patients and healthy subjects. Gastroenterology 1979; 75: 87985.

4 Grundy SM, Metzger AL. A physiological method for estimation of hepatic secretion of biliary lipids in man. Gastroenterology 1972; 62: 1200-17.

5 Lanzini A, Jazrawi R, Northfield TC. Simultaneous quantitative measurement of absolute gallbladder storage and emptying during fasting and eating in humans. Gastroenterology 1987; 92: 852-61.

6 Arvidsson A, Avlan G, Angelin B, Borga O, Nord KE. Ceftriaxone: renal and biliary excretion and effect on the colonic microflora. J Antimicrob Chemother 1982; 10: 207-15.

7 Dujoovne CA, Gustafson JH, Dickey RA. Quantitation of biliary excretion of drugs in man. Clin Pharmacol Ther 1982; 31: 187-94.

8 Gundert-Remy U, Frohnapfel F, Jourdan W, Weber E, Sthiel A. Estimation of biliary excretion of ureido- penicillins in healthy volunteers using marker dilution technique. Br J Clin Pharmacol 1982; 13: 795-801.

9 Shaffer EA, Small DM. Biliary lipid secretion in cholesterol gallstone disease. J Clin Invest 1977; 59: 82840.

10 Everson TG, Lawson MJ, McKinley C, Showalter R, Kern Jr F. Gallbladder and small intestinal regulation of biliary lipid secretion during intraduodenal infusion of standard stimuli. J Clin Invest 1983; 71: 596-603.

11 Jazrawi RP, Kupfer RM, Bridges C, Joseph A, Northfield TC. Assessment of gall-bladder storage function in man. Clin Sci 1983; 65: 185-91.

12 Everson GT, Braverman DZ, Johnson L, Kern Jr F. A critical evaluation of real-time ultrasonography for the study of the gallbladder volume and contraction. Gastroenterology 1980; 79: 40-6.

13 Bjornsson OG, Adrian TE, Dowson J, et al. Effects of gastrointestinal hormones on fasting gallbladder storage patterns in man. Eur J Clin Invest 1979; 9: 293-300.

14 Hyden S. A turbidometric method for determination of higher polyethylene glycols in biological materials. Lantbrukshogskolans Ann 1955; 22: 139-45.

15 Adam HK, Houghton HL, Yates RA, Young J, Donnelly RJ. Pharmacokinetics and tolerance of a 24-h infusion of cefotetan disodium (with and without loading dose) in normal Caucasian volunteers. J Antrimicrob Chemother 1983; 11 [suppl]: 193-9.

16 Talalay P. Enzymic analysis of steroid hormones. Methods Biochem Anal 1960; 8: 119-43.

17 Jazrawi RP, Brown C, Northfield TC. Measurement of biliary lipid mass within the gallbladder in health and in ileal Crohn's disease [Abstract]. Gut 1984; 25: A1141.

18 Aronsson B, Mollby R, Nord CE. Occurrence of Clostridium difficile in antibiotic-associated diarrhea in Sweden. Med Microbiol Immunol 1981; 170: 27-35.

19 Keighley MRB, Lister DM, Jacobs SI, Giles GR. Hazards of surgical treatment due to microorganisms in the bile. Surgery 1974; 75: 578-83.

20 Phillips I, King A, Shannon K, Warren C. Cefotetan: invitro antibacterial activity and susceptibility to -lactamases. J Antimicrob Chemother 1983; 11 [suppl A]: 1-9.

21 Askin JR, Lyon DT, Shull SD, Wagner CI, Soloway RD. Factors affecting delivery of bile to the duodenum in man. Gastroenterology 1978; 74: 560-5.

22 Yates RA, Adam RJ, Donnelly RJ, Houghton HL, Charlesworth EA, Laws EA. Pharmacokinetics and tolerance of single intravenous doses of cefotetan disodium in male Caucasian volunteers. $J$ Antimicrob Chemother 1983; 11 [suppl A]: 185-91. 